\title{
O Programa Mulheres Mil como uma Possibilidade de Autonomia para Mulheres em Vulnerabilidade Social
}

\author{
El Programa Mujeres Mil como una Posibilidad de Autonomía para
}

\author{
Mujeres en Vulnerabilidad Social
}

The Thousand Women Program as a Possibility of Autonomy for Women in

\author{
Social Vulnerability
}

\author{
Patrícia Martins Tavares ${ }^{1}$ \\ Jair Jonko Araujo ${ }^{2}$
}

\begin{abstract}
Resumo
O presente trabalho objetiva apresentar o Programa Mulheres Mil e discutir seu potencial na emancipação das mulheres atendidas pelo mesmo. Desta forma, discorre brevemente acerca dos conceitos de política pública, gênero, vulnerabilidade e empoderamento. A partir dos dados obtidos nos documentos referentes ao Programa e em pesquisas recentes, pode-se inferir que essa política de gênero permite às mulheres que se encontram em situação de vulnerabilidade o acesso a cursos profissionalizantes que podem contribuir para a melhoria de seu potencial produtivo, visando sua inserção no mundo de trabalho, sob a perspectiva de melhoria de suas vidas e de suas famílias.
\end{abstract}

Palavras-Chave: Empoderamento; Gênero; Política Pública; Programa Mulheres Mil.

\section{Resumen}

El presente trabajo tiene como objetivo presentar el Programa Mujeres Mil y discutir su potencial en la emancipación de las mujeres atendidas por el mismo. De esta forma, discurre brevemente acerca de los conceptos de política pública, género, vulnerabilidad y empoderamiento. A partir de los datos obtenidos en los documentos referentes al Programa y en investigaciones recientes, se puede inferir que esa política de género permite a las mujeres que se encuentran en situación de vulnerabilidad el acceso a cursos profesionalizantes que contribuyen a la mejora de su potencial productivo, su inserción en el mercado de trabajo, desde la perspectiva de la mejora de sus vidas y de sus familia

Palabras claves: Empoderamiento; Género; Política Pública; Programa Mujeres Mil.

\begin{abstract}
The present work aims to present the Thousand Women Program and discuss its potential in the emancipation of women attended by the same. In this way, it briefly discusses the concepts of public policy, gender, vulnerability and empowerment. From the data obtained in the documents referring to the Program and in recent research, it can be inferred that this gender policy allows women who are in a vulnerable situation to have access to vocational courses that can contribute to the improvement of their productive potential, aiming at their insertion in the world of work, under the perspective of improving their lives and their families.
\end{abstract}

Keywords: Empowerment; Genre; Public policy; Women's Program Mil.

\footnotetext{
${ }^{1}$ Mestranda em Educação Profissional e Tecnologia, Instituto Federal de Educação, Ciência e Tecnologia Sulrio-grandense - IFSUL; Pelotas, Rio Grande do Sul, Brasil; patimartins87@ gmail.com.

${ }^{2}$ Doutor em Educação, Prof. do Instituto Federal Sul-rio-grandense - IFSUL; Pelotas, Rio Grande do Sul, Brasil, jairaraujo@ifsul.edu.br.
} 


\section{Introdução}

Este trabalho se insere numa pesquisa em andamento cujo objetivo é identificar que sentidos mulheres atendidas por uma oferta educacional do Programa Mulheres Mil no câmpus Pelotas do Instituto Federal Sul-rio-grandense (IFSul) atribuem a esta política. De antemão, indicamos que a pesquisa tem como linha condutora uma concepção complexa de políticas sociais/educacionais, em consonância com a matriz conceitual pós-estruturalista. Neste sentido, não se compreende política na perspectiva linear, ou seja, não se trabalha com o propósito de analisar os processos e os impactos provocados pela implementação de determinada política, com objetivo de verificar a eficácia de determinado programa, na relação custo-benefício (Mainardes, Ferreira e Tello, 2011). As análises e interpretação dos sentidos das políticas serão realizadas com os aportes teóricos e metodológicos do ciclo de políticas, desenvolvido por Ball (1994).

Considerando a concepção deste autor que política é "um conjunto de tecnologias e práticas realizadas e disputadas em nível local - política é ambos, texto e ação, palavras e fatos, tanto o que é intencionado como o que é realizado" (p.10), assumimos que ao mesmo tempo em que uma política está sendo construída está sendo contestada e alterada, pois os "elaboradores/autores" não conseguem controlar o significado de uma determinada política, uma vez que elas serão interpretadas/ressignificadas pelos atores/agentes das diferentes arenas/níveis onde uma política está sendo construída, criando novos significados para a referida política. Nesta perspectiva, assumimos que os sujeitos envolvidos no Programa, constroem sentidos em consonância com as limitações e possibilidade do contexto local onde estão inseridos, independente de intencionalidades da política.

O Programa é dirigido a grupos de mulheres pertencentes a um mesmo território, com histórias de vida e identidades comuns, uma vez que a perspectiva territorial presume a integração de espaços, atores sociais, mercados e políticas públicas. Pressupõe, ainda, a compreensão do território como lugar que possibilita o desenvolvimento de potencialidades individuais e coletivas e o fortalecimento dos vínculos familiares e comunitários.

O Mulheres Mil foi implantado no Brasil, inicialmente, como Projeto Piloto, com o objetivo de promover a inclusão social e econômica de mulheres em situação de vulnerabilidade, a fim de permitir a melhoria do seu potencial de mão de obra, bem como as suas vidas e de suas famílias. Executado inicialmente em 12 estados das regiões norte e nordeste do país, foi idealizado por meio de uma parceria com a Association of Canadian Community Colleges (ACCC) do Canadá, em 2007. 
Diante dos resultados obtidos, o Ministério da Educação (MEC) instituiu nacionalmente, em 2011, o Programa Nacional Mulheres Mil. Com uma metodologia denominada Acesso, Permanência e Êxito, ele passou a ofertar cursos profissionalizantes às mulheres em situação de vulnerabilidade social. São cursos de Formação Inicial e Continuada (FIC), com carga horária em torno de 160 horas que atende públicos específicos de mulheres, utilizando uma metodologia que privilegia temas como direitos e deveres das mulheres, empreendedorismo, economia solidária, saúde, elevação da autoestima, entre outros, buscando promover a inclusão produtiva, a mobilidade no mercado de trabalho e o pleno exercício da cidadania.

Em 2013, o Mulheres Mil passou a integrar o Programa Nacional de Acesso ao Ensino Técnico e Emprego (Pronatec) por meio da iniciativa denominada Bolsa Formação. A oferta é resultado da parceira entre o MEC e o Ministério do Desenvolvimento Social e Combate à Fome (MDS), no âmbito do Plano Brasil Sem Miséria (Pronatec/BSM), articulado com a meta de erradicação da pobreza extrema no país. Ele é executado pelas unidades da Rede Federal de Educação Profissional Científica e Tecnológica.

De acordo com a cartilha do Pronatec, o Programa Mulheres Mil é direcionado a mulheres a partir de 16 anos, chefes de família, em situação de extrema pobreza, cadastradas ou em processo de cadastramento no CadÚnico (sistema que identifica e caracteriza as famílias de baixa renda, para que possam ter acesso aos programas Sociais do Governo Federal), com as seguintes características: em vulnerabilidade e risco social, vítimas de violência física, psicológica, sexual, patrimonial e moral, com escolaridade baixa ou defasada e, preferencialmente, ainda não atendidas pelo Pronatec/BSM. Conforme dados disponíveis no site do Ministério da Educação, o programa faz parte das metas de erradicação da pobreza do Plano Brasil Sem Miséria do Governo Federal.

O Programa Mulheres Mil foi ofertado no câmpus Pelotas do IFSul ${ }^{3}$ entre os anos de 2012 a 2015, sendo ofertadas duas turmas por ano, atendendo uma média de vinte alunas por turma, totalizando oito turmas e cerca de 160 alunas no decorres destes quatro anos. Os cursos ofertados foram: Cuidador de idosos, Empregada doméstica, Auxiliar de educação infantil, Cartonageiro e Pintor de obras.

\footnotetext{
${ }^{3}$ Dados obtidos de maneira informal, através da coordenadora do Programa no instituto, à época, durante o processo inicial de desenho da Pesquisa.
} 


\title{
2. Diálogos sobre gênero
}

Se observarmos a trajetória das mulheres ao longo da história, podemos perceber que desde sempre a mulher precisou lutar para conseguir ocupar um espaço na sociedade, Conforme Louro (1997) mais fortemente no final do séc. XIX podemos falar em feminismo como um movimento social organizado. Destaca ainda (LOURO, 1997 p.15):

\begin{abstract}
$\mathrm{Na}$ virada do século, as manifestações contra a discriminação feminina adquiriram uma visibilidade e uma expressividade maior no chamado "sufragismo", ou seja, no movimento voltado para estender o direito do voto às mulheres. Com uma amplitude inusitada, alastrando-se por vários países ocidentais (ainda que com força e resultados desiguais), o sufragismo passou a ser reconhecido, posteriormente, como a "primeira onda" do feminismo.
\end{abstract}

Conforme Puleo (2004) Gênero é um conceito construído pelas ciências sociais nas últimas décadas para analisar a construção sócio-histórica das identidades masculina e feminina. Dentre as várias autoras que discutem o conceito Gênero, temos Gayle Rubin (França, 2012), antropóloga norte-americana, e para ela o sistema sexo/gênero é um conjunto de arranjos através dos quais uma sociedade transforma a sexualidade biológica em produtos da atividade humana, e na qual estas necessidades sexuais transformadas são satisfeitas. Já para a historiadora estadunidense Joan Scott (1995, p.86), a definição de gênero tem duas partes e diversos subconjuntos "O gênero é um elemento constitutivo de relações sociais baseadas nas diferenças percebidas entre os sexos e o gênero é uma forma primária de dar significado às relações de poder". Para Scott, as questões como o gênero funciona nas relações sociais humanas e como o gênero dá sentido à organização e à percepção do conhecimento histórico só podem ser respondidas a partir de uma discussão de gênero como categoria de análise. A autora afirma também que as abordagens nas análises de gênero se resumem a três posições teóricas, a saber: a primeira, tentativa feminista em explicar as origens do patriarcado; a segunda - marxista - busca um compromisso com as críticas feministas; a terceira - dividida entre o pós-estruturalismo francês e as teorias angloamericanas de relação do objeto - tenta explicar a produção e a reprodução da identidade de gênero do sujeito.

Judith Butler (2003, p.25), filósofa também estadunidense, conceitua gênero:

O gênero não deve ser meramente concebido como a inscrição cultural de significado num sexo previamente dado (uma concepção jurídica); tem que designar também o aparato mesmo de produção mediante o qual os próprios sexos são estabelecidos. Resulta daí que o gênero não está para a cultura como o sexo para a natureza; ele também é o meio discursivo-cultural pelo qual a "natureza sexuada" ou 
um "sexo natural" é produzido e estabelecido como "pré- discursivo", anterior a cultura, uma superfície politicamente neutra sobre a qual age a cultura.

Ultimamente podemos observar muitos esforços na defesa da igualdade de gênero. Temos, por exemplo, a criação da ONU para mulheres em 2010 para unir, fortalecer e ampliar os esforços mundiais em defesa dos direitos humanos das mulheres. Conta com seis áreas prioritárias de atuação, a saber: liderança e participação política das mulheres; empoderamento econômico; fim da violência contra mulheres e meninas; paz e segurança e emergências humanitárias; governança e planejamento; normas globais e regionais. Criação da Lei 11.340, popularmente conhecida como "Lei Maria da Penha", que visa criar mecanismos que coíbam a violência doméstica e familiar contra a mulher.

Entendendo o Programa Mulheres Mil como uma política pública voltada para as mulheres que, dentre outros objetivos, visa a tirá-las de situação de vulnerabilidade social, compreendo que a partir do momento que elas entram no curso abre-se um leque de possibilidades de transformação em suas vidas.

\section{Os sentidos da Vulnerabilidade}

Os textos políticos estão carregados de palavras sem conceito previamente definido, muitas vezes com significados que flutuam com diferentes perspectivas ao longo dos diferentes documentos de uma determinada política. Conforme Mainardes (2006), políticas são intervenções textuais, mas elas também carregam limitações materiais e possibilidades. Ainda, de acordo com Ball (1993), a política como texto entende as políticas como representações que são codificadas de maneira complexa. O autor aponta que os textos não são só o que eles parecem ser em sua superfície, são processos complexos, carregados de contradições e ambiguidades.

Nesta perspectiva, o significante Vulnerabilidade perpassa muitos destes textos do Programa Mulheres Mil, sem definição do que seria "estar vulnerável”. A seguir, apresentaremos uma breve discussão sobre este conceito, no intuito de destacar alguns sentidos para o conceito de "Vulnerabilidade".

Para Katzman (1999) a Vulnerabilidade é entendida como o desajuste entre ativos e a estrutura de oportunidades, proveniente da capacidade dos atores sociais de aproveitar oportunidades em outros âmbitos socioeconômicos e melhorar sua situação, impedindo a deterioração em três principais campos: os recursos pessoais, os recursos de direitos e os recursos em relações sociais. 
Vignoli (2001, p. 2) entende Vulnerabilidade como a falta de acesso às estruturas de oportunidade oferecidas pelo mercado, estado ou sociedade, apontando a carência de um conjunto de atributos necessários para o aproveitamento efetivo da estrutura de oportunidades existentes.

O Atlas da Vulnerabilidade Social (IVS) - plataforma de consulta ao índice de Vulnerabilidade Social dos estados e cidades brasileiras (BRASIL, 2017) -, alimentada com dados do Censo e da Pesquisa Nacional por amostra de domicílio (PNAD) do Instituto Brasileiro de Geografia e Estatística (IBGE), mede o índice de Vulnerabilidade a partir de 16 indicadores organizados em três dimensões a saber: infraestrutura urbana, capital humano e renda e trabalho. A plataforma apresenta uma breve revisão de literatura a fim de conceituar Vulnerabilidade nas perspectivas de Robert Castel (1998) e Caroline Moser (1998).

Conforme informações da plataforma, Castel refere-se à vulnerabilidade social como produto da precária inserção dos indivíduos na sociedade salarial - a qual engendra riscos sociais específicos - Moser e demais autores, vinculados ao Banco Mundial, entendem tal condição como um déficit dos indivíduos ou das famílias, que aparentemente não tem relação com a organização da sociedade capitalista, de mercado e salarial, e cuja superação depende, ou da obtenção de ativos ou da melhor utilização dos ativos disponíveis. A plataforma incorpora alguns aspectos das duas teorias, porém não se filia a nenhuma delas. Vulnerabilidade, de acordo com dados da plataforma, decorre de processos sociais amplos, contra os quais o indivíduo sozinho não possui meios para agir e cujos rumos só o Estado, através de políticas públicas, tem condições de alterar. Dessa forma, Vulnerabilidade social na perspectiva da plataforma, diz respeito à ausência ou insuficiência de ativos que podem, em grande medida, ser providos pelo Estado, em seus três níveis administrativos (União, estados e municípios), constituindo-se, assim, num instrumento de identificação das falhas de oferta de bens e serviços públicos no território nacional.

Temos, ainda, a definição do Aurélio (2000) trazendo que o verbete “vulnerável” diz do ponto pelo qual alguém ou algo pode ser atacado.

Dada a pluralidade de sentidos atribuídos ao significante "Vulnerabilidade" compreendemos, neste estudo, em acordo com Bruseke (2006), que "estar vulnerável” referese a um grupo de fatores, sobrepostos de diversas maneiras e em várias dimensões, de modo a tornar o indivíduo ou grupo mais suscetível aos riscos e contingências. Para Bruseke (2007) "o discurso do risco é uma maneira de se comunicar num campo de eventos contingentes. Tal categoria é sempre, para o homem, uma ameaça hipotética”. 


\section{Refletindo sobre Políticas Públicas}

Políticas públicas são as várias metas e planos que o governo desenvolve para alcançar o bem estar da sociedade e do interesse público sendo o Estado e a Sociedade Civil responsáveis pela discussão, ação e execução (SANTOS \& FREITAS, 2014).

Fábio Guedes (2006) argumenta, historicamente, comparando com as políticas de bem estar social em diversos países, a desarticulação das políticas de assistência social no Brasil. Até 1930 as políticas públicas no país foram bastante efêmeras, significando apenas pacotes de programas desarticulados entre si e objetivando cooptar as classes subalternas e proporcionar-lhes as condições propícias à sua reprodução. O autor ainda afirma que o sistema de seguridade social no Brasil, no contexto e nas características que assumiram a luta de classes e a composição dos blocos hegemônicos, ao contrário das experiências de países europeus no período pós-II Guerra Mundial, não reuniu as condições suficientes para ser constituído. Com o avanço de modelos neoliberais gerencias, cada vez menos o Estado investe recursos em políticas que visem garantir as condições mínimas de existência a populações socialmente desfavorecidas.

No cenário das políticas públicas temos, no Brasil, a política em questão - Programa Mulheres Mil - política que, vista de maneira superficial, sem uma análise profunda, parece resolver a situação de extrema pobreza a partir da capacitação das mulheres beneficiadas pelo programa. Mas ao aprofundar estudos sobre a política, , percebemos que a capacitação não tem, por si, necessariamente, como consequência tirá-las da situação de extrema pobreza. Os cursos ofertados até podem permitir que elas adentrem no mundo do trabalho. Mas não se trata de uma simples relação diploma-trabalho. Até mesmo porque, os cursos têm curta duração, sendo impossível o desenvolvimento de profissões complexas, que exijam aprofundamento de saberes, o que lhes proporcionaria, talvez, possibilidade de ocupar espaços no mundo do trabalho com maiores rendimentos financeiros.

\section{Trilhando algumas considerações}

O Programa Mulheres Mil é uma política Pública desenvolvida para mulheres em vulnerabilidade social. Uma de suas diretrizes, como exposto anteriormente, é defender a igualdade de gênero. É nítido, nos documentos oficiais do Programa, que o mesmo pretende criar oportunidade de capacitação profissional visando tirar as mulheres da situação de vulnerabilidade em que se encontram. Esse é o texto político, o discurso político. Em consonância com a teoria de Ball (1994), a política é ressignificada pelos sujeitos envolvidos no processo, está sujeita à interpretação e recriação - e produzem efeitos e consequências que 
podem representar mudanças e transformações significativas em relação à política original concebida. Dessa forma, será que, na prática, cursos de 160h realmente conseguem propiciar um conhecimento que inclua estas pessoas em um mundo do trabalho tão competitivo como o que temos atualmente? Certos estudos apontam que o programa tem caráter excludente, pois proporciona uma formação rasa, que as mantém a margem da sociedade e em profissões pouco valorizadas.

Mas não podemos deixar de observar os benefícios claros que o mesmo proporciona para essas mulheres. A partir de estudos preliminares acerca do Programa, por meio da produção em relação ao mesmo, de teses e dissertações, de documentos oficiais, contatos informais preliminares com gestores de cursos realizados no IFSul câmpus Pelotas e mulheres que realizaram os cursos é possível inferir que a experiência educacional vivenciada no Programa contribui positivamente na vida das alunas que concluíram os cursos. Através deste material constata-se que as mulheres, de alguma forma, passaram por transformações em suas vidas. Muitas, não imaginavam terem capacidade de estudar em uma Instituição Federal. Outras, não se viam capazes de aprenderem um ofício. Para algumas, o simples fato de sair de casa para estudar, ainda que não se inserissem no mundo do trabalho após a conclusão do curso, já fora motivo suficiente para sentirem-se empoderadas e donas de suas histórias.

A questão do empoderamento não pode ser deixada de lado. Empoderamento, autonomia, autoestisma elevada, são fatores comuns que se destacam nos estudos do Programa. E estes fatores, por si só, talvez já bastassem para a melhoria na vida das mesmas, pois podem ser o ponto de partida, para que se sintam motivadas a seguir em frente em busca de uma qualificação mais consistente, se assim desejarem.

No decorrer desta pesquisa, pretende-se, através de entrevistas, analisar os sentidos e significados que as mulheres atendidas pelo Programa, no IFSul - câmpus Pelotas, atribuem ao mesmo. Também, se buscará compreeder as singularidades da oferta educacional no IFSul - câmpus Pelotas.

\section{Referências}

BALL, Stephan. Education reform: a critical and post-structural approach. Buckingham: Open University Press, 1994.

BALL, Stephen. What is policy? Texts, trajectories and toolboxes. In: BALL, Stephan. Education reform: a critical and post-structural approach. Buckingham: Open University Press, 1994. (p.14-27) 
BALL, S.J. What is criticism? A continuing conversation? A rejoinder to Miriam Henry. Discourse, London, v. 14, n. 2, p. 108-110, 1993b. In: MAINARDES, Jeferson; FERREIRA, M. dos Santos; TELLO, César. Análise de políticas: fundamentos e principais debates teóricos-metodológicos. In: Políticas educacionais: questões e dilemas. São Paulo: Cortez, p. 143-172, 2011.

BALL, S.J.; BOWE, R. Subject departments and the "implementation" of National Curriculum policy: an overview of the issues. Journal of Curriculum Studies, London, v. 24, n. 2, p. 97-115, 1992.

BRASIL, Atlas da Vulnerabilidade Social. Disponível em: <http://ivs.ipea.gov.br/index.php/pt/> Acesso em: $01 \mathrm{dez} .2017$.

BRASIL, Lei de 15 de outubro de 1827, Manda criar escolas de primeiras letras em todas as cidades, vilas e lugares mais populosos do Império. Disponível em: <http://www.planalto.gov.br/ccivil_03/leis/lim/LIM-15-10-1827.htm> Acesso em: 20 jul. 2017.

BRASIL, Lei $N^{o} 11.340$, de 7 de agosto de 2006, dispõe sobre a criação dos Juizados de Violência Doméstica e Familiar contra a Mulher; altera o Código de Processo Penal, o Código Penal e a Lei de Execução Penal; e dá outras providências. Disponível em: <http://www.planalto.gov.br/ccivil_03/_ato2004-2006/2006/lei/111340.html> Acesso em: 15 out. 2016.

BRASIL, Mulheres Mil oferece 100 mil oportunidades de capacitação. Disponível em: $<$ http://www.brasil.gov.br/educacao/2017/02/mulheres-mil-oferece-100-mil-oportunidadesde-capacitacao > Acesso em: 09 nov. 2016.

BRASIL, Portaria $n^{\circ} 1015$, de 21 de julho de 2011, que institui o Programa Mulheres MilEducação, Cidadania e Desenvolvimento Sustentável. Disponível em: $<$ http://portal.mec.gov.br/index.php?option=com_docman\&view=download\&alias=8589portaria1015-220711-pmm-pdf\&category_slug=agosto-2011-pdf\&Itemid=30192>Acesso em: 16 nov. 2017.

BRASIL, Portaria $n^{o} 1015$, de 21 de julho de 2011, que institui o Programa Mulheres MilEducação, Cidadania e Desenvolvimento Sustentável. Disponível em: $<$ http://portal.mec.gov.br/index.php?option $=$ com_docman\&view $=$ download\&alias=8589portaria1015-220711-pmm-pdf\&category_slug=agosto-2011-pdf\&Itemid=30192> Acesso em: 16 nov. 2016.

BRUSEKE, Franz. Josef. Risco e Contingência. Os paradigmas da modernidade e sua contestação. Revista Brasileira de Ciências Sociais, 1 ed. Florianópolis: Editora Insular, 2006, 69-80 pp. In: Seminario Vulnerabilidad, CEPAL, Santiago de Chile, 2001, In CANÇADO, Taynara Candida Lopes; SOUZA, Rayssa Silva de; CARDOSO,Cauan Braga da Silva, Trabalhando o conceito de Vulnerabilidade Social. Disponível em: <http://www.abep.org.br/ abeporgb/abep.info/files/trabalhos/trabalho_completo/TC-10-45499-410.pdf > Acesso em: 10 nov. 2017. 
BRUSEKE. Franz Josef. Risco e Contingência. 2007. Disponível em: <http://www.scielo.br/scielo.php?script=sci_arttext\&pid=S0102-69092007000100006> Acesso em: 18 nov. 2017.

BUTLER, Judith. Problemas de Gênero: feminismo e subversão da identidade. Tradução de Renato Aguiar. Rio de Janeiro: Editora Civilização Brasileira, 2003.

COSTA, Ana Alice Alcântara. Gênero, poder e empoderamento das mulheres, 2010. Disponível em: <https://pactoglobalcreapr.files.wordpress.com/2012/02/5-empoderamentoana-alice.pdf< Acesso em: 16 nov. 2016.

COUTINHO, Jordania Medeiros. As trilhas do empoderamento feminino no IFbaianoCampus Uruçuca. 2015. Disponível em: <

https://sucupira.capes.gov.br/sucupira/public/consultas/coleta/trabalhoConclusao/viewTrabalh oConclusao.jsf?popup=true\&id_trabalho=3559306 > Acesso em: 13 ago. 2017.

DUARTE, Kelly Cristine Ferreira Prado. Identidade de gênero feminino no programa Mulheres Mil: verdades, poder e subjetivação. 2016. Disponível em: < https://sucupira.capes.gov.br/sucupira/public/consultas/coleta/trabalhoConclusao/viewTrabalh oConclusao.jsf?popup=true\&id_trabalho=4044952 > Acesso em: 08 ago. 2017.

FILHO, Ari de Araujo Vilar de Melo. Avaliação da implementação do programa nacional de acesso ao ensino técnico e emprego Pronatec mulheres MIL: um estudo de caso. 2016 Disponível em :

<https://sucupira.capes.gov.br/sucupira/public/consultas/coleta/trabalhoConclusao/viewTrabal hoConclusao.jsf?popup=true\&id_trabalho=3679548> Acesso em: 08 ago. 2017.

FRANÇA, Matheus. Gayle Rubin e o "The Traffic in Women": apontamentos iniciais. Disponível em: <https://ensaiosdegenero.wordpress.com/2012/04/16/o-conlceito-de-generopor-gayle-rubin-o-sistema-sexogenero/> Acesso em: 09 out .2017.

GIL, Antonio Carlos. Como elaborar projetos de pesquisa. 5 ed. São Paulo: Atlas, 2010.

GODINHO, Tatau (org.); SILVEIRA, Maria Lúcia (org.). Políticas Públicas e igualdade de gênero. Filosofia e gênero: da memória do passado ao projeto de futuro. Alicia H. Puleo Caderno $n^{\circ} 8$ da Coordenadoria Especial da Mulher. São Paulo, 2004. Disponível em: <http://library.fes.de/pdf-files/bueros/brasilien/05630.pdf> Acesso em: 12 out. 2017.

GOMES, Fábio Guedes. Conflito social e welfare state: Estado e desenvolvimento social no Brasil. RAP Rio de Janeiro 40(2):201-36, Mar./Abr. 2006.

HOGAN, Daniel Joseph; MARANDOLA, Eduardo Jr. Para uma conceituação interdisciplinar da vulnerabilidade. Disponível em:

$<$ http://www.nepo.unicamp.br/publicacoes/livros/vulnerabilidade/arquuivos/arquuivos/vulner ab_cap_I_pgs_21-50.pdf> Acesso em: 02 ago. 2017.

KAZTMAN, R. (Coord.). Activos y estructuras de oportunidades. Estudio sobre las raíces de la vulnerabilidad social en el Uruguay. Montevideo: Oficina del Programa de las Naciones Unidas para el Desarrollo (PNUD) y Oficina de la CEPAL en Montevideo, LC/MVD/R, 1999. (n.180). 
LOURO, Guacira Lopes. Gênero, sexualidade e educação. Petrópolis, RJ: Vozes, 1997. LOURO, Guacira Lopes. Mulheres na Sala de Aula. In: PRIORE, Mary Del. (Org.). História das Mulheres no Brasil, 10 ed. São Paulo: Contexto, 2015. (pg. 443 - 481)

MAINARDES, Jeferson; FERREIRA, M. dos Santos; TELLO, César. Análise de políticas: fundamentos e principais debates teóricos-metodológicos. In: Políticas educacionais: questões e dilemas. São Paulo: Cortez, p. 143-172, 2011.

MARCONI, Marina de Andrade; LAKATOS, Eva Maria. Fundamentos de metodologia científica. São Paulo: Atlas S.A, 2003.

MINISTÉRIO DA EDUCAÇÃO. Programa Mulheres Mil. Disponível em: <http://portal.mec.gov.br/programa-mulheres-mil> Acesso em: 08 nov. 2016

OLIVEIRA, Silvelena Alves de Araújo. Mulheres, conquistando espaços dentro do Instituto Federal de Educação Ciência e Tecnologia do Ceará (IFCE) - Campus Iguatu. São Leopoldo, 2014. Disponível em: < https://sucupira.capes.gov.br/sucupira/public/consultas/coleta/trabalhoConclusao/viewTrabalh oConclusao.jsf?popup=true\&id_trabalho=1992748 > Acesso em: 15 ago. 2017

ONU MULHERES. Princípios de Empoderamento das Mulheres. [S. 1.]: Onu Mulheres [2010]. Disponível em: <http://www.onumulheres.org.br/onu-mulheres/sobre-a-onumulheres/> Acesso em: 12 out. 2017. Revisão de Tomaz Tadeu da Silva a partir do original inglês (SCOTT, J. W.. Gender and the Politics of History. New York: Columbia University Press, 1988. PP. 28-50.), de artigo originalmente publicado em: Educação \& Realidade, vol. 15, no 2, jul./dez. 1990. Tradução da versão francesa (Les Cahiers du Grif, no 37/38. Paris: Editions Tierce, 1988.) por Guacira Lopes Louro.

SANTOS, Maria Aparecida de Paula; FREITAS, Carlos Cesar Garcia. O Programa Mulheres Mil no Brasil, ações para a inclusão social da mulher. Anais do Congresso Internacional de Administração. Paraná, 2014.

SCOTT, Joan Wallach. Gênero: uma categoria útil de análise histórica. Educação \& Realidade. Porto Alegre, vol. 20, nº 2, jul./dez. 1995, pp. 71-99.

SILVA, Carla Renata Capilé. Programa Mulheres Mil: Subjetividade, Inclusão e Governabilidade. 2015. Disponível em: < <https://sucupira.capes.gov.br/sucupira/public/consultas/coleta/trabalhoConclusao/viewTrabal hoConclusao.jsf?popup=true\&id_trabalho=2802564> Acesso: em 10 ago. 2017.

SILVA, Silvana Sônia Oliveira da. A construção identitária de mulheres: análise das narrativas do livro Mulheres Mil/do sonho à realidade. 2014. Disponível em: < https://sucupira.capes.gov.br/sucupira/public/consultas/coleta/trabalhoConclusao/viewTrabalh oConclusao.jsf?popup=true\&id_trabalho=975449 > Acesso em: 12 ago. 2017.

SILVERLI, Márcia Ferreira. "Mulheres Mil” como política pública de inclusão social: uma análise do empoderamento feminino. 2016. Disponível em:

https://sucupira.capes.gov.br/sucupira/public/consultas/coleta/trabalhoConclusao/viewTrabalh oConclusao.jsf?popup=true\&id_trabalho=4986082 Acesso em: 10 ago. 2017 
TRIBUNAL REGIONAL ELEITORAL. 82 anos da conquista do voto feminino no Brasil. Disponível em: <http://www.tre-es.jus.br/imprensa/noticias-tre-es/2014/Fevereiro/82-anosda-conquista-do-voto-feminino-no-brasil> Acesso em: 06 nov. 2016.

VIGNOLI, J. R. Vulnerabilidad Demográfica en América Latina: qué hay de nuevo? In: Seminario Vulnerabilidad, CEPAL, Santiago de Chile, 2001, In CANÇADO, Taynara Candida Lopes; SOUZA, Rayssa Silva de; CARDOSO, Cauan Braga da Silva, Trabalhando o conceito de Vulnerabilidade Social. Disponível em:

<http://www.abep.org.br/ abeporgb/abep.info/files/trabalhos/trabalho_completo/TC-10-45499-410.pdf > Acesso em: 10 nov. 2017. 